\title{
The experimental study of the effect of screw and adhesive connection in the variation of cold-formed roof truss framing system
}

\author{
Wilman Adi Santoso ${ }^{1}$, Budi Suswanto ${ }^{1}$, Endah Wahyuni ${ }^{1}$, Indra Komara ${ }^{1,2}$ \\ ${ }^{1}$ Departement of Civil Engineering, Institut Teknologi Sepuluh Nopember, Surabaya, \\ Indonesia \\ ${ }^{2}$ Departement of Civil Engineering, Institut Teknologi Adhi Tama Surabaya, Surabaya, \\ Indonesia
}

wilman.adisantoso@gmail.com

\begin{abstract}
Connections with screws are used extensively to connect cold-formed steel (CFS) structural element, especially in the roof truss framing system. However, these connections cannot be relied upon to transfer loading due to the small thickness plates that result in more slender elements which are susceptible to local or distortional buckling and have low stiffness. Therefore, some improvements are made in this study by adding adhesive as the alternative connection. Three types of roof truss framing system are designed with a different connection, i.e. screw, adhesive and the combination of screw and adhesive. The study aims to investigate the behavior of frames connection through experimental studies with the given static load until the frame structure collapses, with attention to their initial (pre-slip) stiffness, elongation, and load-deformation capacity. As a result, the stiffness of adhesive connection given a lower value than screw connection. It is indicated of the delamination process, that the combination connection implied the better behavior with $50 \%$ screw reduction as well as increasing the load-deformation capacity with $69.7 \mathrm{~mm}$, three times higher than the screw connection.
\end{abstract}

Keywords: cold-formed steel, screw connection, adhesive connection, load-deformation capacity.

\section{Introduction}

Cold-formed steel (CFS) structure is a type of construction that can be used as an alternative in a roof truss design in both residential building and other commercial construction. This is because the frame system using CFS has small dimensions, does not require scaffolding, is easy to install so that the construction time will be faster. CFS is also more environmentally friendly compared to the use of wood construction and reinforced concrete [1]. At present, the CFS tensile strength has reached $550 \mathrm{MPa}$ [2], however, compared with hot-rolled steel sections with the same weight of the material, the smaller thickness plates used for CFS sections results in more slender sectional elements which are susceptible to local or distortional buckling and have low stiffness, especially in connections. This shortcoming limits the potential of CFS members in larger span and taller buildings. Therefore, making some improvements in the connections of CFS structures is significant for the extension of the application of cold-formed steel [3][4], and [5]. 
In recent years, a limited amount of experimental studies on CFS connections have been conducted by many researchers around the world including the implementation of the CFS codes [6][7]. Nevertheless, only a few were involved with adhesive connections. For example, Laboube and Sokol [8] identify the screw connection with the design parameters in the form of the effect of the placement pattern, number, and distance of the screw on the joint that is usually used in roof truss construction. As a result, with the size of the screws and one type of CFS section, increasing the number of screws will reduce the strength per screw on the joint.

The use of adhesives in connection with a thin structural element is one of the alternatives for improving connection performance. This is considered because several benefits such as more rigid, simpler, widely distributed, have excellent damping characteristics and reduce local failure due to elongation of screw holes [9]. Naito [10] explains that joint strength is strongly influenced by the thickness of the adhesive where tensile stress decreases as the thickness of the adhesive increases. Anwar et al. [11] examined axial and flexural performance in mild steel structures using epoxy resin adhesive and polyester resin adhesive. As a result, the combination of the connection between the adhesive and the screw on the structure can prevent premature structural collapse.

Furthermore, Komara [12] conducted a research development with a model of variations in the number of screws and the area of adhesive in the connection of lightweight steel roof truss connection including to evaluate the structure of material behavior [13][14], and [15]. The result is that the combination of the connection between the screw and adhesive can increase the capacity 3-4 times the screw or adhesive joint. However, the study carried out only static of direct tensile test; it is necessary to do experimental testing again as a control parameter with a perfect skeletal testing scheme based on a span, load, and original crosssectional dimensions such as the original condition.

\section{Research Methodology}

The initial stage in this study was the design of CFS cross section capacity and determining the number of screws based on the design parameter. A total of three types roof-frame structure were carried out on test specimens were a tensile load transferred from flag plate to the beam web (see Figure 3 ). The specimens are divided to identify the system, namely Howe, Fink and Pratt which are illustrated in Figure 1 with implying the same height of $750 \mathrm{~mm}$ with the midspan frame equal to $3000 \mathrm{~mm}$.

Various connection type was included, screw, adhesive, and combination connection, respectively. Experimental data were gathered using potentiometers and failure pictures aiming to investigate the stiffness of the framing system. Tensile coupon test was also considered from the previous study in order to determine the material properties of the CFS sections [12].

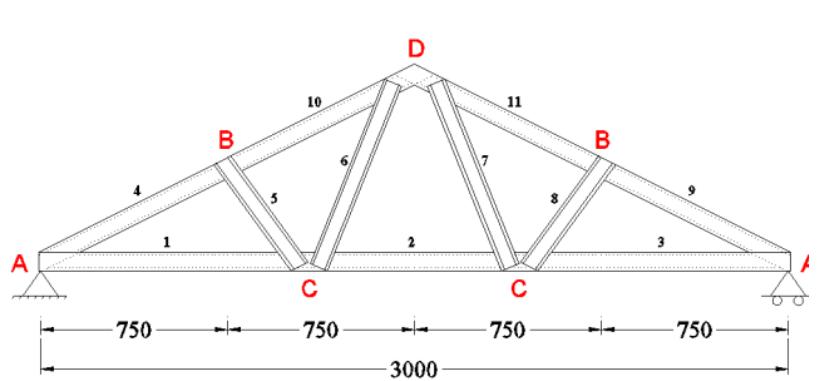

(a) Howe truss frame type

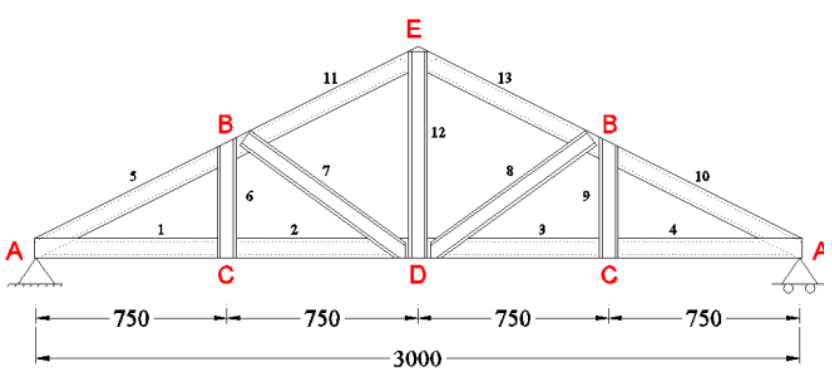

(b) Fink truss frame type 


\section{KCTECH ITATS}

The $1^{\text {st }}$ International Conference on Advanced Engineering and Technology - 2018

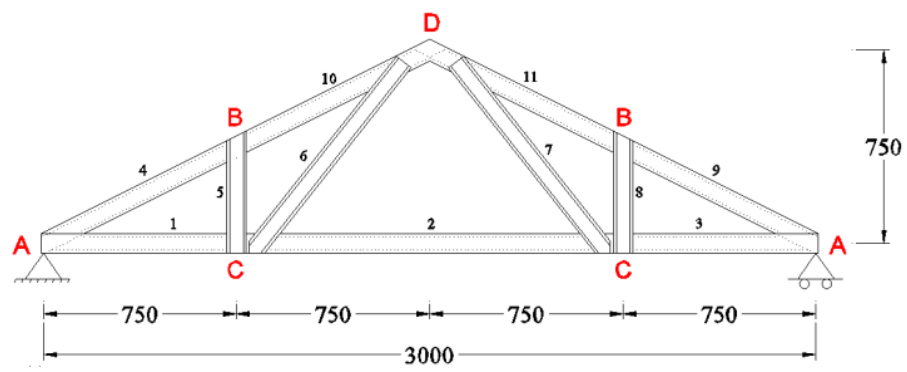

(c) Pratt truss frame type

Figure 1. Geometry shape of the specimen of a truss framing system

\subsection{Test procedure and instrumentation}

Before making a test specimen, preliminary preparation is needed. These preparations are in the form of surface pretreatment/removal of the galvanized layer using sandpaper so that the adhesive can adhere well to the adherent. The screw in the combination connection is installed when the condition of the adhesive is still wet because if screw mounting is done when the adhesive has hardened, it will indicate cracking in the adhesive around the screw hole due to pressure during the tightening process.

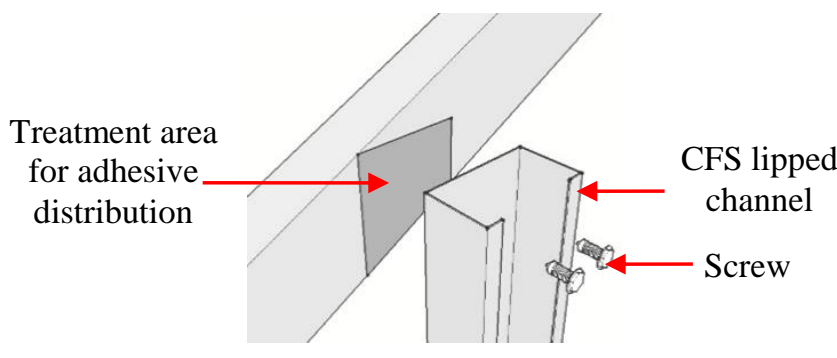

(a)
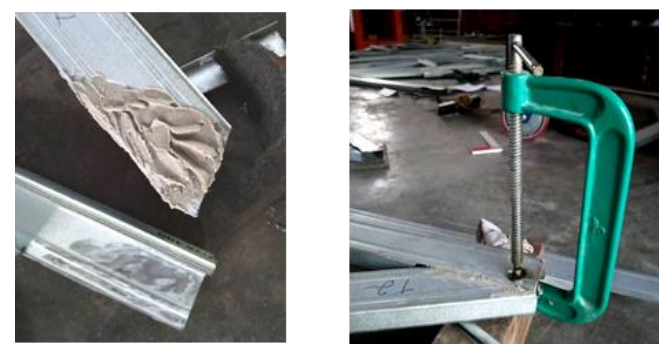

(b)

Figure 2. CFS connection in detail; (a) Screw-adhesive connection implementation, (b) A given adhesive $\mathrm{t}=1 \mathrm{~mm}$

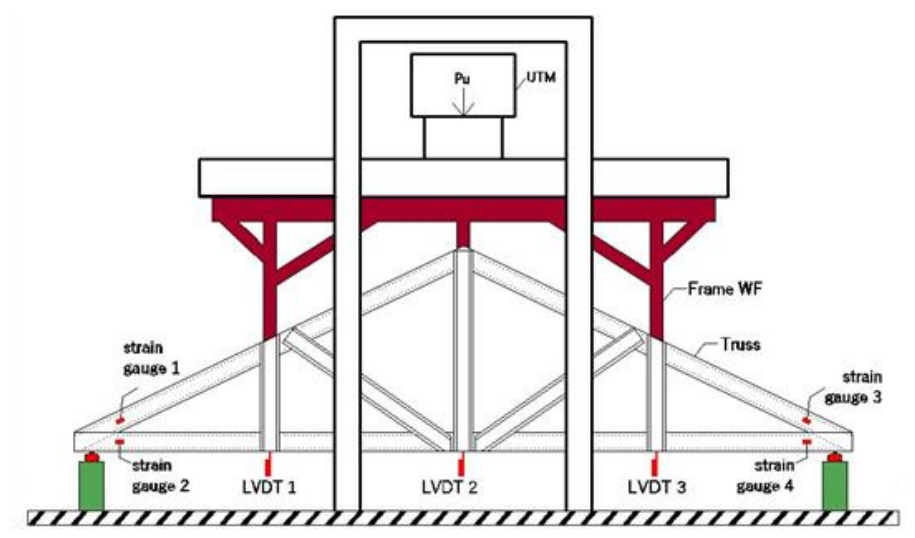

(a) Loading scheme

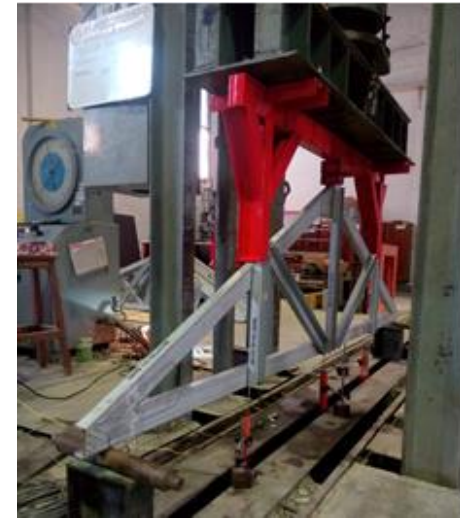

(b) Test instrumentation

Figure 3. Specimens test set-up 
The test set-up is illustrated in Figure 3. A fink truss frame containing LVDT to control the loaddeformation behavior represents the screw and adhesive material in the structural roof framing system. The thicknesses of the sheets were chosen according to the most popular profile used in practice and were selected $1 \mathrm{~mm}$. It is selected the same for all specimens. M12 self-drilling screw used in conjunction for Howe and Pratt specimens. Fink specimen is only used adhesive material as the primary connection. Csection of CFS $75 \times 35 \times 12 \mathrm{~mm}$ was used as the main of the roof frame. In order to obtain the actual yield strength and stress-strain relationship for the tested specimens, tensile coupon tests, refer to Komara [15], were considered in accordance with the standards [7].

The specimens were assembled, and the self-drilling screws were hand-tightened until snug with a wrench, reflecting the practice in the industry. It can be seen from Figure $2 b$. The arrangement of the frame is chosen by the several of works, generally considered as the mid-rise residential building. The frame was placed between the pin point of simply placement. The set-up is modified by using additional of loading frame (it can be seen on the red figure of set-up scheme using WF frame) of a $1000 \mathrm{kN}$ ESH universal testing machine and the frame was loaded until failure. The hydraulics was used in displacement control mode, adopting the displacement rates. The initial (pre-slip) loading range, were a high stiffness of the connection was encountered, as low displacement rate of typically $0.1 \mathrm{~mm} / \mathrm{min}$ was imposed, while this rate was increased once slip of the connection took place.

\section{Test Result and Observation}

The test arrangement illustrated in Figure 3, it is noted that the load is applied eccentrically with reference to the plane of the frame in three points. This displays the actual situation in the roof framing system, where the same eccentricity is presented between external load through the section in the frame. It is found that maintaining this eccentricity was paramount in order to observe realistic behavior in the test as well as the effect of, for example, screw tilting and buckling. The failure of the frame, induced by the material connection against the type of frame, was observed in all tests. It is noted that the deformations during the instrumentation by using a different connection, i.e., self-drilling screw and adhesive leading to the informed of the failure modes.

Howe frame, Figure 4a, illustrates the maximum load values $1860 \mathrm{~kg}, 580 \mathrm{~kg}$, and $1800 \mathrm{~kg}$, respectively for the screw, adhesive and combination connections. Combination connections in this frame display almost constant and appropriate results where reading the high load capacity with a value of deformation $47.40 \mathrm{~mm}$. In the other hand, screw and adhesive connection informed a low peak condition with nonuniform behavior with the first peak of deformation under $30 \mathrm{~mm}$. Fink frame, Figure 4b, shows a smaller load capacity value than Howe frame, except for adhesive connection where the structure can reach a maximum load capacity of $1050 \mathrm{~kg}$ with the elongation $57 \mathrm{~mm} .17 .86 \%$ gap of screw connection due to this frame to Howe frame. Most of the specimen in this frame experienced local buckling, the fink frame is a failure before reaching the maximum designed capacity. It aforementioned of several mistakes during placement or set-up position. The last, Pratt frame, Figure 4c, occurs in the combination connection of the maximum load-deformation capacity to $1600 \mathrm{~kg}$ with $64.5 \mathrm{~mm}$ stroke. The load relationship graph with deflection shows a pattern of load increases which tends to be stable until the failure. The failure indication is relatively the same as the Fink frame due to large bending of C-section. It is lower $18.75 \%$ than screw connection. 


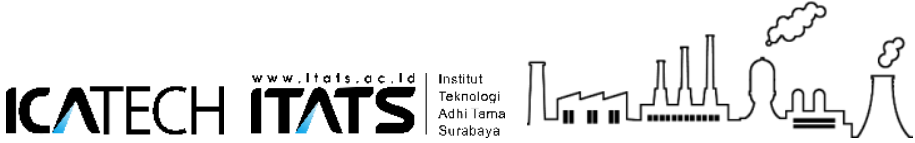

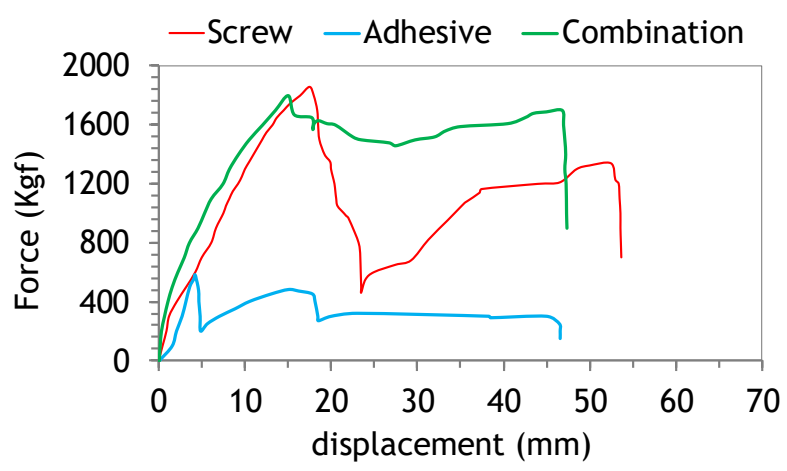

(a) Howe roof frame

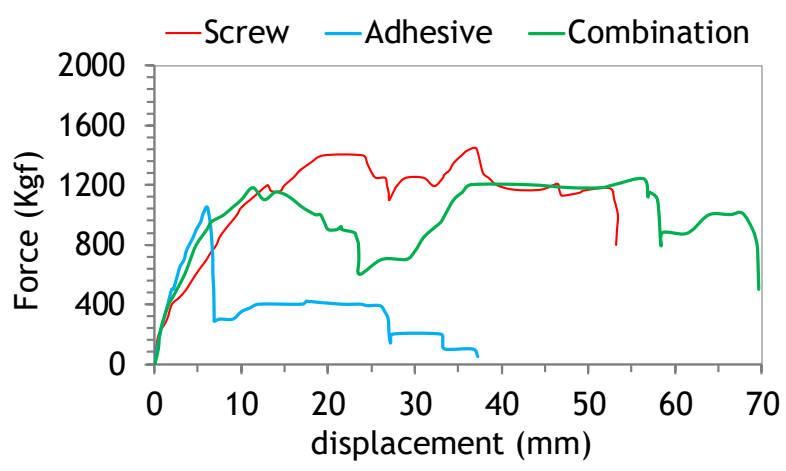

(a) Fink roof frame

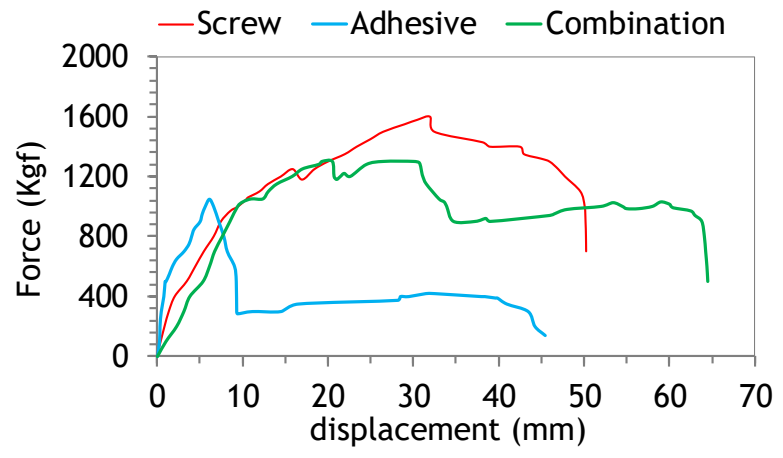

(c) Pratt roof frame

Figure 4. Influence of the type framing system on the various connection capacity

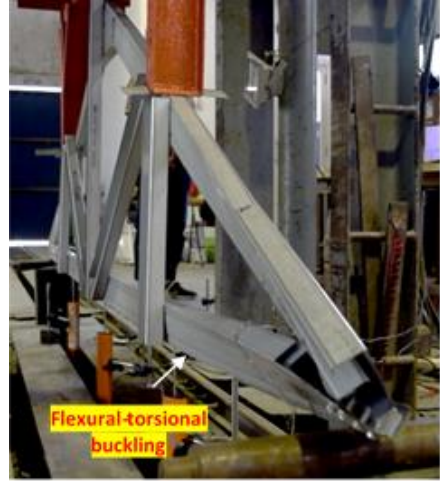

(a) Howe

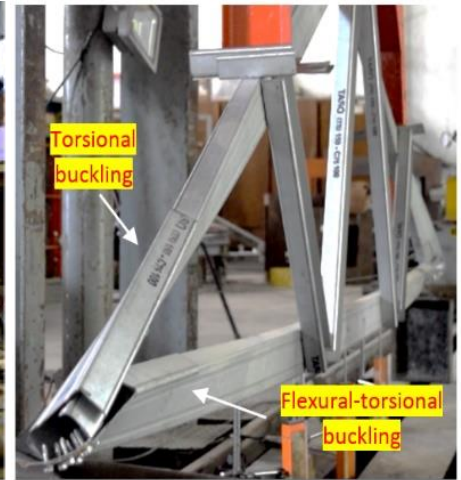

(b) Fink

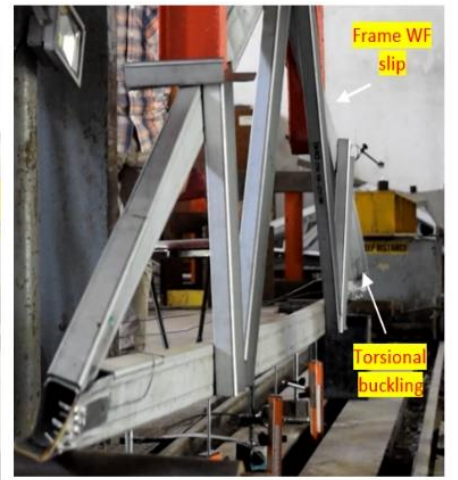

(c) Pratt

Figure 5. Typical failure example of roof framing system by using self-drilling screw connection

As for the results of the load-deformation behavior of each specimen, it was found, the effect of adhesive on the joint has a significant impact on the frame performance, especially to improve the ductility of the structure. Adhesive material helps to minimize the fracture caused by its connection. The results, illustrated in Figure 4 while detail of experimental work illustrated in Figure 5, carried out the similar behavior and can be used as an alternative design to reduce the fracture of the connection caused by screws holes. 


\section{Conclusion}

After testing of roof framing system of the screw and adhesive connections series under various frames and loaded in monotonic with three-point load, it can be concluded that:

1. It is indicated of the delamination process, that the combination connection implied the better behavior with $50 \%$ screw reduction as well as increasing the load-deformation capacity with $69.7 \mathrm{~mm}$, three times higher than the screw connection.

2. Enhanced adhesive connection in roof framing system was approximately $5-10 \%$ times stronger than the conventional screw connection in ductility, while connection with adhesive material, combination connection, were about three times stronger.

3. Enhanced screw connections had typical stiffnesses, while adhesive connection less stiffened that screw connection but combination connection will affect approximately three to four times stiffer than the connection with screw or adhesive alone. It is reviewed after the failure stage of the roof frame.

4. The frame with combination connection had a very small fracture than the screw and adhesive connection. In addition, the use of combination connection will also reduce the use of screw and will eliminate the failure based on the screw hole significantly.

\section{References}

[1] W. Easterling, T. Murray, F. Charney, C. Roberts, M., and Setareh, "Experimental and analitical studies of the behaviour of cold-formed steel roof truss elements," Virginia, 2005.

[2] X. Zhao, "Investigations on structural interaction of cold-formed steel roof purlin-sheet system," University of Birmingham, 2014.

[3] Hancock JG, "Design for distorsional buckling of flexural members," Thin-walled Struct, vol. 27, no. 1, pp. 3-12, 1998.

[4] B. Schafer and T. Pekoz, "Laterally braced cold-formed steel flexural members with edge stiffened flanges," J. Struct. Engg, vol. 125, no. 2, pp. 118-127, 1999.

[5] J. Hancock, T. Murray, and D. Ellifritt, Cold-Formed Steel Structure to the AISI Specification. New York: Marcek Dekker Inc, 2001.

[6] Badan Standarisasi Nasional Indonesia (BSNI), "Struktur Baja Canai Dingin (SNI 7971:2013)," Jakarta, 2013.

[7] AISI, "North American Spesification fot the design of Cold-Formed Steel Structural Members," American Iron and Steel Institute and Canadian Standards Association, 2007.

[8] R. Laboube and M. Sokol, "Behavior Of Screw Connections In Residential Construction," J. Struct. Enguneering, vol. 128, pp. 115-118, 2002.

[9] J. Brandon, "Wood Joint and Adhesive," 2010.

[10] K. Naito, M. Onta, and Y. Kogo, "The Effect of Adhesive Thickness on Tensile and Shear Strength of Polymide Adhesive," Int. J. Adhes. Adhes., vol. 36, pp. 77-85, 2012.

[11] S. Anwar, P. Suprobo, and E. Wahyuni, "Axial and Flexural Performance of Adhesive Connection on Cold-Formed Steel Structures," Int. J. Technol., vol. 6, no. 4, pp. 699-708, 2015.

[12] I. Komara, E. Wahyuni, and P. Suprobo, "A study on Cold-formed Steel Frame Connection: A review," IPTEK J. Technol. Sci., vol. 28, no. 3, pp. 83-89, 2017.

[13] I. Komara, T. Kivanc, E. Wahyuni, and P. Suprobo, "The experimental study of cold-formed steel truss connections capacity: Screw and adhesive material," J. Curr. Constr. Issue, vol. 3, no. 2, pp. 229-24, 2017.

[14] I. Komara, T. Kivanc, E. Wahyuni, and P. Suprobo, "Experiment on cold-formed steel c-section joint with screw and adhesive material," MATTER IJST, vol. 3, no. 2, pp. 51-63, 2017.

[15] I. Komara, E. Wahyuni, P. Suprobo, and T. Kivanc, "Assessing the Tensile Capacity of Cold-Formed Steel Connections using Self-Drilling Screws and Adhesive Materials," IJASEIT, vol. 8, no. 2, pp. 397-404, 2018. 